\title{
Effect of particle size on processing of bioactive glass powder for atmospheric plasma spraying
}

\author{
E. Cañas ${ }^{*}$, M. Vicent, E. Bannier, P. Carpio, M.J. Orts, E. Sánchez \\ a) Instituto de Tecnología Cerámica (ITC), Asociación de Investigación de las \\ Industrias Cerámicas (AICE), Universidad Jaume I, 12006 Castellón, Spain \\ Eugeni Cañas Recacha Telephone number: (+34) 964342424 \\ Email: ecanas@uji.es_ Fax number: (+34) 964342425 \\ Mónica Vicent Cabedo \\ Email: monica.vicent@itc.uji.es \\ Emilie Bannier \\ Email: emilie.bannier@itc.uji.es \\ Pablo Carpio Cobo \\ Email: pablo.carpio@itc.uji.es \\ María José Orts Tarí \\ Email: mariajose.orts@itc.uji.es \\ Enrique Sánchez Vilches \\ Email: enrique.sanchez@itc.uji.es
}




\section{Abstract}

The work addresses the effect of the particle size of a bioactive glass feedstock on the processing and microstructure of the resulting coatings obtained by atmospheric plasma spraying (APS). It was observed that the reduction of particle size negatively affects the flowability of the powder. In addition the thermal behaviour (weight losses, glass transitions, crystallisations, etc) also depended on the particle size of the glass powder. No coating was obtained with the coarser fractions (higher than $200 \mu \mathrm{m}$ ) due to their low melting degree in the plasma. For the intermediate fractions (200 to $63 \mu \mathrm{m})$ coatings were obtained but insufficient particle melting was produced. On the contrary, the finest fraction $(<63 \mu \mathrm{m})$ needed a fluidiser which enabled the samples to be sprayed.

Keywords: Bioactive glass powders; Feedstock flowability; Feedstock thermal behaviour; Atmospheric plasma spraying; Bioactive glass coatings

\section{Introduction}

From the sixties there is an important need for bioactive materials to heal or replace damaged areas of the body, due to the ability of these materials to prevent fibrous encapsulation when compared with an inert implant. Bioactive materials include hydroxyapatite (HA) ceramics, glasses, glass-ceramics and surface-active composite materials $[1,2]$. The most studied of the above materials are glasses, known as bioactive glasses (BGs), because of their higher bioactivity index [3].

BGs are materials based on mixtures of oxides from the $\mathrm{SiO}_{2}-\mathrm{CaO}-\mathrm{MgO}-\mathrm{Na}_{2} \mathrm{O}-\mathrm{K}_{2} \mathrm{O}-$ $\mathrm{P}_{2} \mathrm{O}_{5}$ system. The first BG, developed by L. Hench et al., was $45 \mathrm{~S} 5$ bioactive glass or Bioglass ${ }^{\circledR}$, which consists of $45 \% \mathrm{SiO}_{2}, 24.5 \% \mathrm{CaO}, 24.5 \% \mathrm{Na}_{2} \mathrm{O}$ and $6 \% \mathrm{P}_{2} \mathrm{O}_{5}$ (all percentages in wt\%) [4].

BGs preparation techniques include both melting (fusing and crushing) and sol-gel methods [5]. Employing the sol-gel technique, BGs exhibit more bioactivity than those obtained by melting in spite of having lower mechanical properties.

BGs are the most promising materials for bone grafting in several clinical applications, such as orthopaedic, dental, maxillofacial and otolaryngological [6]. Nevertheless, BGs applications are limited due to their brittleness and poor mechanical properties. In order 
to solve these problems, BGs can be deposited onto a bioinert substrate to obtain a composite that improves its mechanical strength without changing its bioactivity [4].

There are many techniques to coat a substrate, usually metallic alloys, with BGs. These techniques can be enamelling, sol-gel method, electrophoretic deposition, laser cladding and thermal spraying techniques (plasma spraying and high-velocity oxy-fuel). Nonetheless the most employed technique to spray BGs, since 1980, is thermal spraying, specifically atmospheric plasma spraying (APS) due to its low cost and industrial feasibility [1-4].

The literature shows many papers about optimisation of plasma spray conditions to obtain BG coatings by APS. Most of these papers also include the characterisation of the resulting coatings [7-12]. However, very few papers have dealt with the effect of the particle size of the bioactive glass feedstock on the processing and final microstructure of the obtained coatings. This aspect is of paramount importance when a glass powder feedstock must be fed into the plasma torch. Fine particle size is required for the powder to sufficiently melt and then adhere on the substrate during splat (melted particle) deposition in the APS process [13]. Moreover too fine particles dramatically impair powder flowability making it difficult or impossible the pneumatic transport of the powder from the container to the plasma torch. Besides the glass powder particle size strongly affects the liquid phase sintering of the as-deposited glass splats as well as the evolving of gas bubbles occurring during the rapid sintering of melted glass particles $[14,15]$. In other words, particle size of the BG feedstock is expected to drastically impact on the microstructure of the final coatings and therefore on their final properties. Consequently, the present work aims at addressing the effect of the particle size of a given BG composition prepared by fusing and crushing on the flowability and thermal behaviour of the powder feedstock. The studied BG powder fractions were obtained from a frit by milling and sieving. Then the different BG powder fractions were sprayed onto metallic substrates by APS. The microstructure of the obtained coatings was examined. The final purpose of the research is to provide the necessary information to contribute to optimise the feeding of BG powder feedstocks in the APS process as well as the microstructure of the resulting coatings. 


\section{Experimental}

\subsection{Feedstock preparation}

A mixture of analytical grade $\mathrm{SiO}_{2}, \mathrm{Ca}_{3}\left(\mathrm{PO}_{4}\right)_{2}, \mathrm{Na}_{2} \mathrm{CO}_{3}$ and $\mathrm{CaCO}_{3}$ was melted in the home-made rotary furnace showed in figure 1, to get the frit. The mixture of raw materials was introduced into the furnace on the left side, whereas the melt was collected on the right side. The maximum temperature reached into the furnace was $1450{ }^{\circ} \mathrm{C}$.

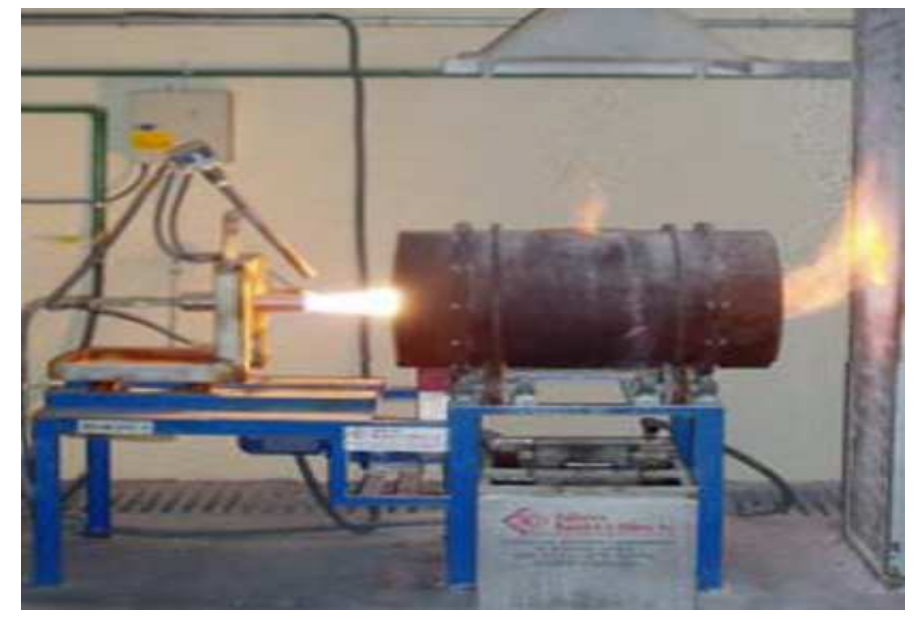

Figure 1 Rotatory furnace employed to obtain the frit

The melt was quenched into water and a BG frit was obtained. The chemical composition of the frit (Table 1) was determined by wavelength dispersive X-ray fluorescence spectrometry (AXIOS, PANalytical, The Netherlands). Table 1 shows the nominal and as-melted glass composition. As observed the frit composition is close to the nominal one. The frit was dry milled in a hammer mill. The milled powder was sieved to obtain different powder size fractions, which were conditioned and used as APS feedstocks. The different size fractions obtained are detailed in table 2. The morphology of both coarse and fine fractions, with the typical angular shape of a milled frit particle, can be observed in figure 2 . 
Table 1 Nominal and as-melted chemical composition of the frit

\begin{tabular}{lcccc}
\hline Composition (wt\%) & $\mathrm{SiO}_{\mathbf{2}}$ & $\mathbf{P}_{\mathbf{2}} \mathbf{O}_{\mathbf{5}}$ & $\mathbf{C a O}$ & $\mathrm{Na}_{2} \mathbf{O}$ \\
\hline Nominal & 45.0 & 6.0 & 24.5 & 24.5 \\
As-melted & 47.6 & 5.3 & 23.1 & 24.0 \\
\hline
\end{tabular}

Table 2 Size fractions obtained from the BG powder

\begin{tabular}{lccccc}
\hline $\begin{array}{l}\text { Powder fraction } \\
\text { reference }\end{array}$ & BGGS & BGGS1 $^{*}$ & BGGS2 & BGGS3 & BGGS4 \\
\hline $\begin{array}{l}\text { Particle size distribution } \\
(\boldsymbol{\mu m})\end{array}$ & $700-200$ & $400-200$ & $200-100$ & $150-63$ & $<63$ \\
\hline $\begin{array}{l}\text { Representative size of } \\
\text { each fraction }(\boldsymbol{\mu m})\end{array}$ & 450 & 300 & 150 & 107 & 63 \\
\hline
\end{tabular}

${ }^{*}$ The percentage of BGGS1 fraction included in the BGGS fraction is $37.2 \pm 0.8 \%$.

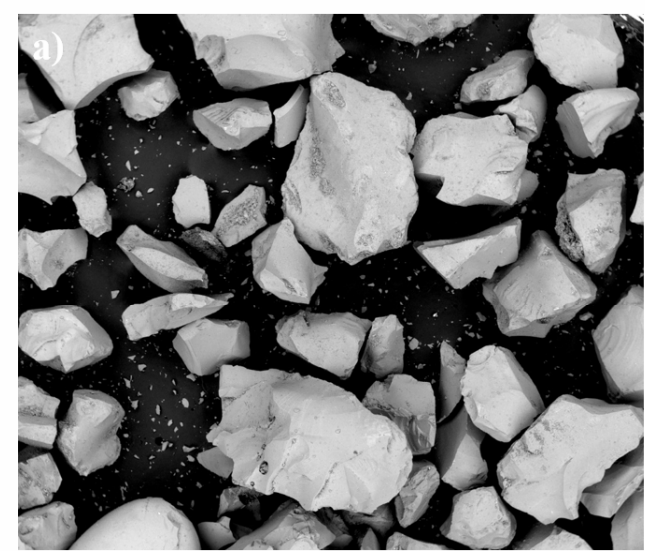

$\overline{500 \mu \mathrm{m}}$

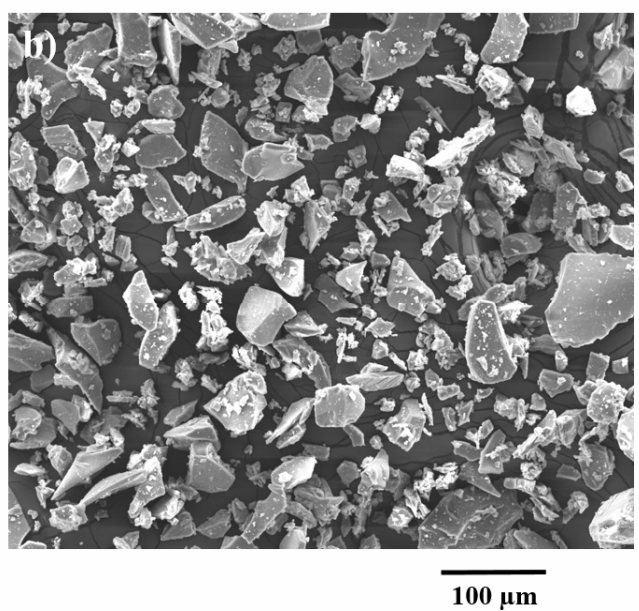

$100 \mu \mathrm{m}$

Figure 2 FEG-ESEM morphology of both (a) coarse (BGGS) and (b) fine (BGGS4) powder fractions

\subsection{Feedstock characterisation techniques}

The amorphous/crystalline character of the different size fractions was determined by X-ray diffraction (XRD) using a diffractometer (Advance diffractometer, Bruker Theta-Theta, Germany). The analysis was performed with $\mathrm{Cu} \mathrm{K} \alpha$ radiation $(\lambda=1.54183$ $\AA$ ), generator settings of $30 \mathrm{kV}$ and $40 \mathrm{~mA}$ and data were collected in a $2 \theta$ range of 5$90^{\circ}$ with a step size of $0.02^{\circ}$ and a scanning speed of $0.5 \mathrm{~s} \mathrm{step}^{-1}$. 
Flowability of the BG fractions was determined by means of two different methods, namely Hausner ratio (HR) and angle of repose $\left(\alpha_{M}\right)$. Hausner ratio represents a method to estimate the flowability-cohesiveness of a given powder. Due to its simplicity HR has been extensively used to characterise APS feedstocks [16,17]. HR is defined as the quotient of the tapped density to the bulk (or poured) density of the powder. On the other hand to determine the angle of repose, a home-made device (Figure 3) was used which consisted in a powder holder coupled to an angle protractor. The holder filled with powder rotates until the powder falls. Then, the clock hand hitched to the holder indicates the angle of repose.

Due to the sensitivity of the BG powder to moisture, flowability tests of some fractions were also carried out with samples which had been left in contact with humid ambient in a climatic chamber in order to determine changes in flowability with adsorbed water [18]. The powder fraction was dried in an oven at $110{ }^{\circ} \mathrm{C}$ and then cooled at room temperature in a desiccator. The dry powder was then introduced in the climatic chamber (WK3, Weiss Umwelttechnik, Germany) at $20{ }^{\circ} \mathrm{C}$ and $60 \%$ relative moisture and the adsorbed water was measured by weighing after 24 hours inside the chamber so as to ensure that equilibrium was reached. These temperature and humidity conditions try to reproduce the typical conditions operating in the laboratory during plasma spray experiments

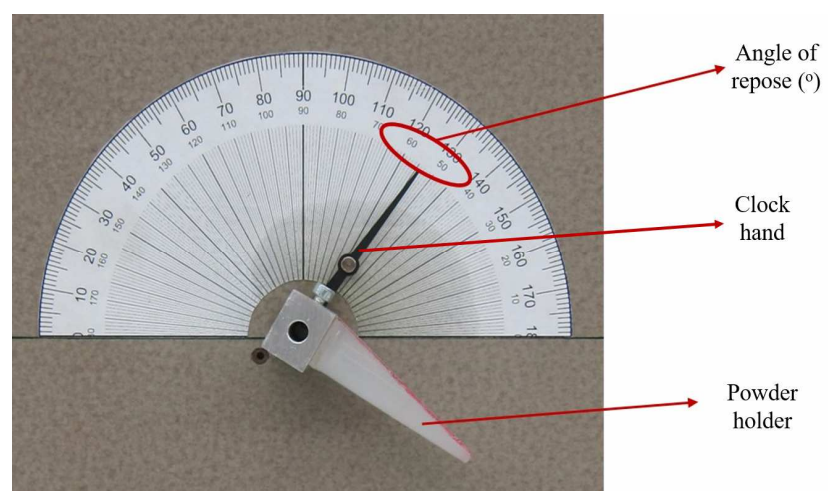

Figure 3 Device for the measurement of the angle of repose

The feedstocks thermal behaviour was investigated by simultaneous thermal analysis (DTA-TG) and heating microscopy. DTA-TG tests (TGA/SDTA 851e, Mettler Toledo, Switzerland) were carried out using a platinum crucible in air atmosphere, with a heating rate of $10{ }^{\circ} \mathrm{C} \min ^{-1}$ until a maximum temperature of $1200{ }^{\circ} \mathrm{C}$. In order to complement these tests, a heating microscope (Misura 3, Expert Systems Solutions, Italy) was used 
and some characteristic temperatures for the powders were determined $[19,20]$. Cylindrical test samples of the powder fractions were prepared by pressing and, in the heating microscope, were subjected to a thermal cycle at a heating rate of $25{ }^{\circ} \mathrm{C} \mathrm{min}{ }^{-1}$ up to $1250^{\circ} \mathrm{C}$.

\subsection{Coating deposition and characterisation}

The different size fractions of the BG powder were sprayed onto metallic substrates by APS. Previously to deposition, the substrates (AISI 304) were grit-blasted and cleaned. Grit-blasting was performed using black corundum with a pressure of $4.2 \mathrm{~Pa}$, and then the substrates were cleaned with ethanol. Surface roughness $\left(\mathrm{R}_{\mathrm{a}}\right)$ of grit-blasted and cleaned substrates was measured with a roughness tester (HOMMELWERKE T8000, Hommelwerke GmbH, Germany). Roughness was $2.2 \pm 0.1 \mu \mathrm{m}$.

The APS facility used comprises a plasma gun (F4-MB, Sulzer Metco, Germany) managed by a six axis robot (IRB 1400, ABB, Switzerland). In the plasma gun, the torch generation was accomplished using argon as primary plasma gas and hydrogen as secondary plasma gas. Spray conditions used were the same for all feedstocks as detailed in table 3. Powders were fed into the plasma torch by pneumatic transport employing argon as carrier gas.

Table 3 Plasma spray conditions used

\begin{tabular}{l|c}
\hline $\mathbf{A r}\left(\mathbf{s l p m}{ }^{*}\right)$ & 25 \\
$\mathbf{H}_{\mathbf{2}}\left(\mathbf{s l p m}{ }^{*}\right)$ & 15 \\
$\mathbf{I}(\mathbf{A})$ & 600 \\
Plasma average enthalpy $\left(\mathbf{M J ~ k g}^{\mathbf{- 1}}\right)$ & $30-35$ \\
Spraying distance (m) & 0.11 \\
Spraying velocity $\left(\mathbf{m ~ s}^{\mathbf{- 1}}\right)$ & 1 \\
Powder mass flow $\left(\mathbf{k g ~ s}^{\mathbf{- 1}}\right) \cdot \mathbf{1 0}^{\mathbf{4}}$ & 2.5 \\
\hline${ }^{*}$ Standard litre per minute &
\end{tabular}

The microstructure of the obtained coatings was observed in a field-emission gun environmental scanning electron microscope (FEG-ESEM) (QUANTA 200FEG, FEI Company, USA), and their amorphous/crystalline character was determined by XRD. 


\section{Results and discussion}

\subsection{Effect of powder particle size on the feedstock flowability}
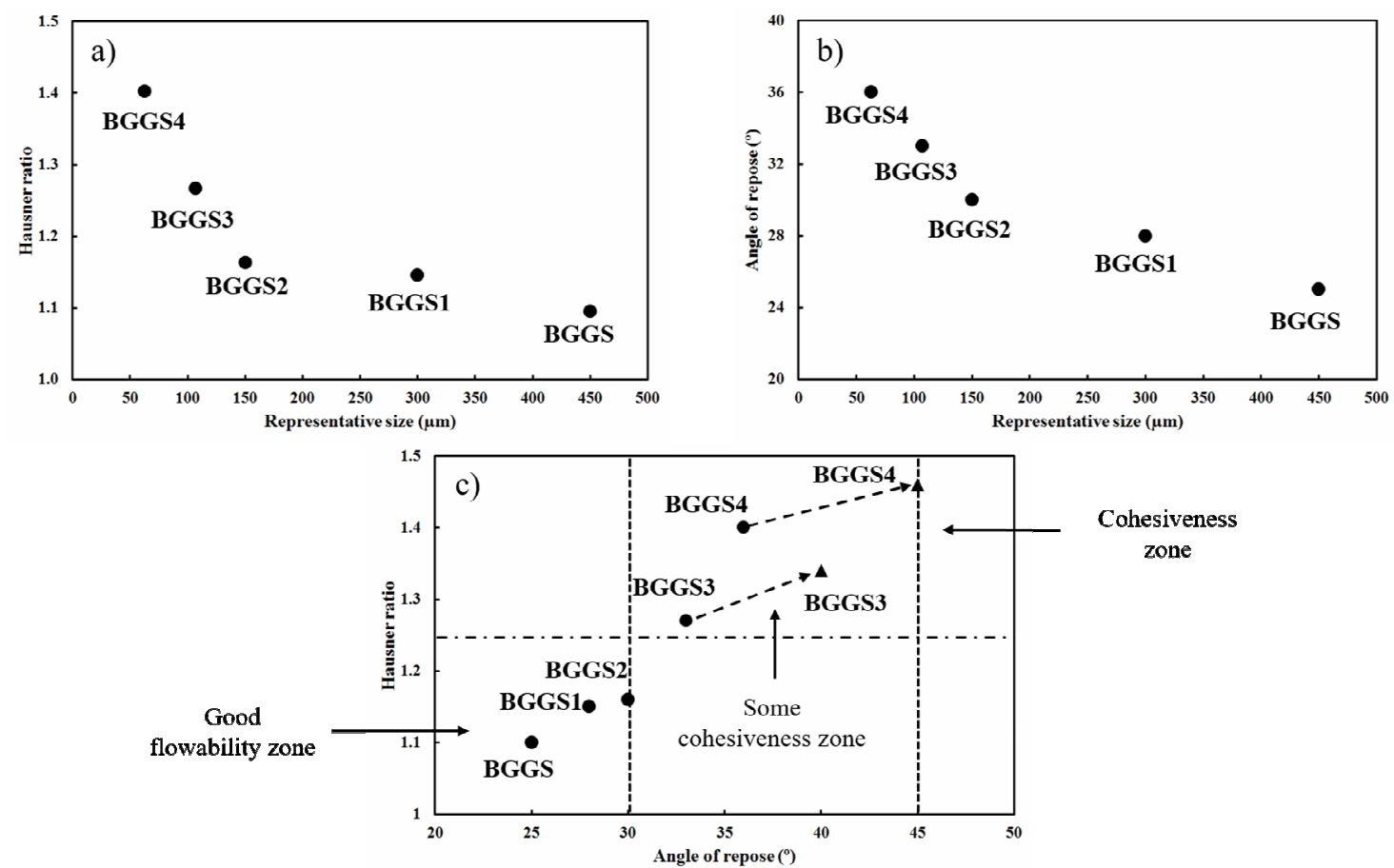

Figure 4 Flowability tests versus mean particle size of the tested glass powder fractions: (a) Hausner ratio, (b) Angle of repose and (c) Hausner ratio versus angle of repose for dry (•) and moist ( $\boldsymbol{\Delta})$ powders

Figure $4 \mathrm{a}$ plots the results of HR tests for the different glass powder fractions. As expected HR increases (flowability decreases) as the particle size of the powder is reduced. This is because when the frictional forces between particles increase the difference between the tapped (vibrated) powder density and the as-poured powder density also tends to rise. Free-flowing powders display HR lower than 1.25 [21]. Thus, samples can be considered as free-flowing powders except those with particles smaller than $150 \mu \mathrm{m}$ (BGGS3 and BGGS4). In fact, when the particle size of the powder becomes increasingly smaller the adhesion forces between particles overcame the gravity forces, which predominate for coarse particles. Findings obtained with the other test (Figure $4 \mathrm{~b}$ ) ratify the effect of the particle size on flowability: the finer the particle size of the powder the higher the angle of repose is, i.e there is a clear flowability decrease as particle size is reduced. According to literature, for angles below $30^{\circ}$ powder has good flowability, angles comprising $30-45^{\circ}$ give some cohesiveness, angles between $45-55^{\circ}$ lead to cohesiveness and for angles higher than $55^{\circ}$ powder displays remarkable cohesiveness [22,23]. The correlation of the data obtained from both 
flowability measurement tests was plotted in figure 4c. As observed there are three different flowability zones in function of the HR and angle of repose. Coarse fractions (BGGS, BGGS1 and BGGS2) are in the good flowability zone in comparison with the fine fractions (BGGS3 and BGGS4) that are in the some cohesiveness zone. From the data acquired, it is then possible to obtain a good correlation between the two methods in both zones confirming the validity of these simple techniques to assess the flowability of powder feedstocks to be used in APS processes.

In addition flowability tests (HR and angle of repose) were also carried out with some samples which stayed inside the climatic chamber (at $20^{\circ} \mathrm{C}$ and $60 \%$ relative moisture) and for $24 \mathrm{~h}$ in order to allow the samples to adsorb their equilibrium moisture. The samples tested were BGGS3 and BGGS4, which corresponded to the smallest particle size fractions. Figure $4 \mathrm{c}$ collects the flowability findings (triangle dots) of these two samples. These data show a significant worsening of flowability (increasing of HR and angle of repose values) after a $24 \mathrm{~h}$ soaking time in the climatic chamber. This change in flowability can only be attributed to the fact that the bioactive glass powder samples are highly hygroscopic [18]. As expected, the amount of adsorbed water increases when particle size decreases, due to the increase of specific surface area. Adsorbed water on the powder surface markedly impairs the flowability of the samples, in particular of the finest powder due to the increasing of the adhesion forces associated with water [24]. As a consequence both samples shift to the cohesiveness zone in figure 4c, specially the finest powder (BGGS4).

In an APS experiment, the powder feedstock can stay for some period of time (between 15-30 min) in contact with room air inside the container of the plasma equipment before it is fed into the torch. That allows the powder to adsorb water. With the aim to assess the changes in water adsorbed with time and its effect on the flowability of the finest powder feedstock the water adsorbed inside the climatic chamber $\left(20{ }^{\circ} \mathrm{C}, 60 \%\right.$ relative moisture) as well as the angle of repose were monitored with time up to 8 hours. Figure 5 plots the variation of the adsorbed water and the angle of repose with the soaking time of the sample inside the climatic chamber. As it can be seen, there is a good parallelism between the amount of adsorbed water and the flowability of the powder. Thus as the water is adsorbed the flowability decreases being this decrease much more significant during the first hour of contact between the powder and the humid air. This is because the first layers of water dramatically increase the molecular adhesion forces by reducing particle surface asperities while the successive water layers 
become less efficient for this purpose [24]. The adsorbed water as well as the angle of repose seem to stabilise after 5 hours of soaking time in the climatic chamber. From figure 5 it can be concluded that in 30 min the powder can adsorb more than $0.2 \%$ of water resulting in a significant increase of angle of repose from $33^{\circ}$ to $35.5^{\circ}$ and consequently in an impairing of flowability. In fact, the high cohesiveness rise observed in the BGSS4 sample after being in contact with room air for some time can block the feeding of this feedstock to the plasma torch.

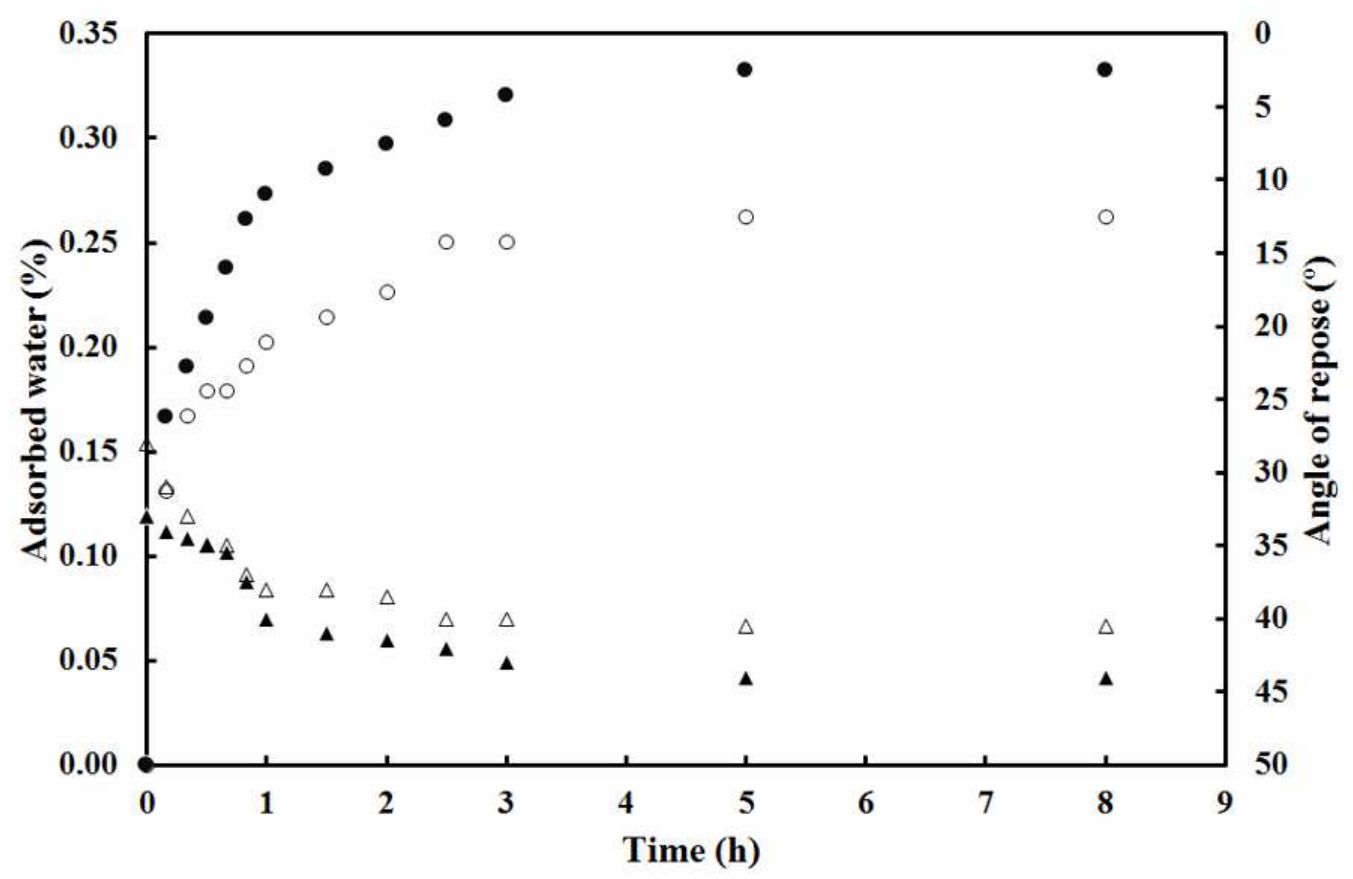

Figure 5 Variation of the adsorbed water and angle of repose of the finest powder fraction (BGGS4) with time exposure to $60 \%$ relative humidity air at $20^{\circ} \mathrm{C}$. Bold points for sample without fluidiser and hollow points for sample with fluidiser

\subsection{Effect of powder particle size on the thermal behaviour of the feedstock}

Figure 6 shows the XRD pattern of the BGGS fraction. The other powder fractions exhibited analogous patterns. As expected, this diffractogram corresponds to fully vitreous material. Thus, all fractions display amorphous structure without any devitrifying phase occurring during melting or crushing of the frit. Consequently, all BG powder fractions seem to be, at first, suitable to obtain bioactive glass coatings as reported elsewhere [25]. 


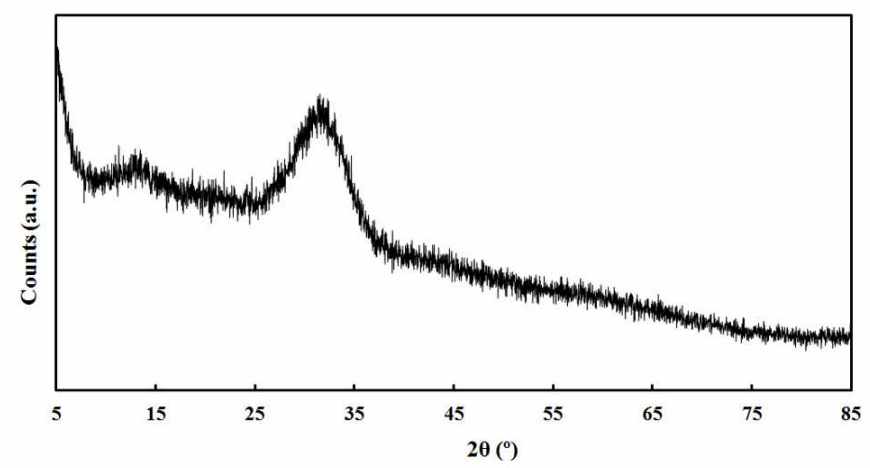

Figure 6 XRD pattern of BGGS powder fraction

The shrinkage-temperature diagram and the characteristic temperatures [20] obtained from heating microscope tests for BGGS, BGGS1, BGGS2 and BGGS3, are detailed in figure 7 and table 4, respectively.

Table 4 Characteristic temperatures of BGGS, BGGS1, BGGS2 and BGGS3 fractions

\begin{tabular}{lcccc} 
Characteristic temperatures $\left({ }^{\circ} \mathbf{C}\right)$ & BGGS & BGGS1 & BGGS2 & BGGS3 \\
\hline First shrinkage $\left(\mathbf{T}_{\mathbf{F S}}\right)$ & 660 & 630 & 625 & 605 \\
Maximum shrinkage $\left(\mathbf{T}_{\mathbf{M S}}\right)$ & 730 & 710 & 700 & 690 \\
Softening point $\left(\mathbf{T}_{\mathbf{S P}}\right)$ & 1180 & 1170 & 1170 & 1170 \\
Half ball $\left(\mathbf{T}_{\mathbf{H B}}\right)$ & 1185 & 1180 & 1180 & 1175 \\
Flow point $\left(\mathbf{T}_{\mathbf{F P}}\right)$ & 1190 & 1185 & 1185 & 1180 \\
\hline
\end{tabular}




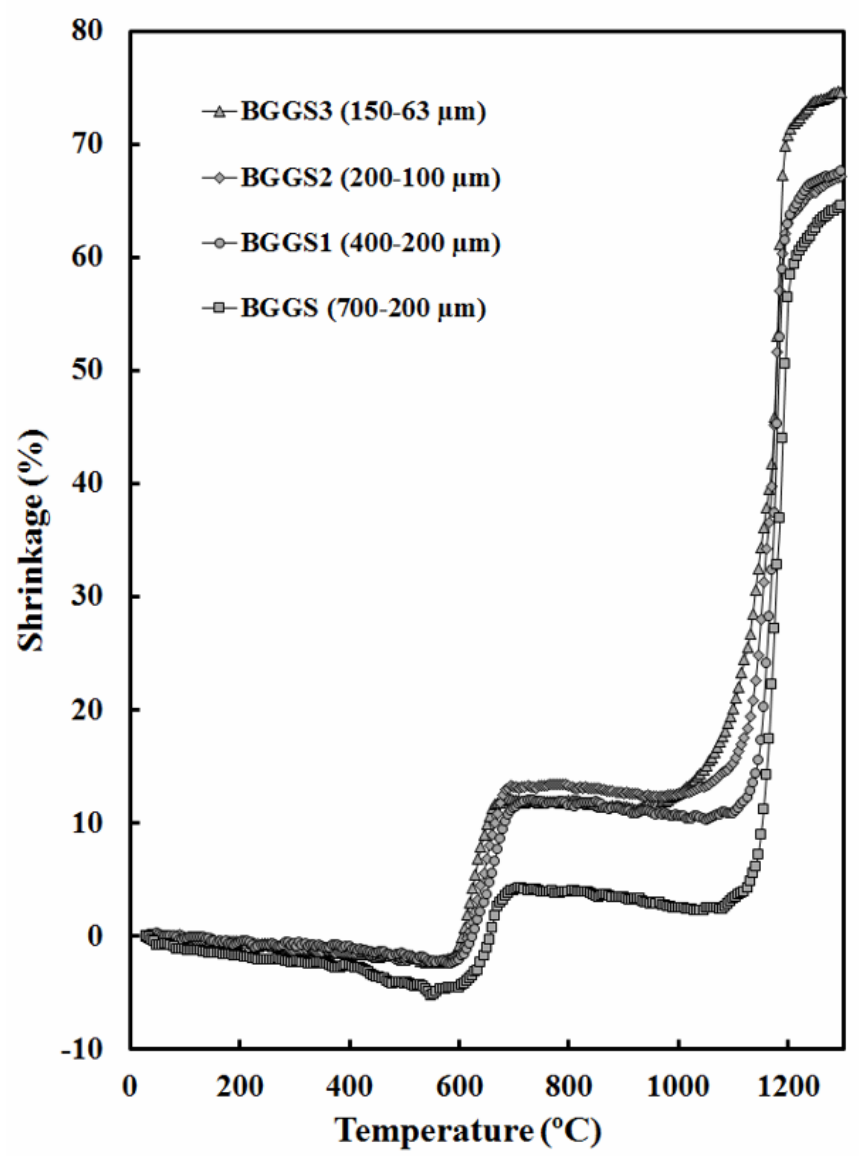

Figure 7 Shrinkage-temperature diagrams for BGGS, BGGS1, BGGS2 and BGGS3 powder fractions obtained in the heating microscope

No significant differences in the characteristic temperatures were observed except for the first shrinkage temperature $\left(\mathrm{T}_{\mathrm{FS}}\right)$. As it can be observed, the particle size defines when particles start sintering. Hence, the smaller the particle size, the lower the temperature at which shrinkage starts. For all particle sizes, it can be observed that in the temperature range $700-1000{ }^{\circ} \mathrm{C}$ devitrification takes place and as a result sintering (shrinkage) stops. In order to identify the phases that crystallize, an amount of BG powder was heated on a ceramic substrate with a corundum layer to prevent the adhesion of both materials. The sample was heated at $25{ }^{\circ} \mathrm{C} \mathrm{min}{ }^{-1}$ to a maximum temperature of $800{ }^{\circ} \mathrm{C}$, and the resulting material was quenched to avoid changes on cooling. XRD of this sample (Figure 8) shows a sodium calcium silicate phase with combeite structure $\left(\mathrm{Na}_{6} \mathrm{Ca}_{3} \mathrm{Si}_{6} \mathrm{O}_{18}\right)$ as major phase and of a sodium calcium phosphate phase with rhenanite structure $\left(\mathrm{NaCaPO}_{4}\right)$ as minor phase [26-28]. The corundum peak corresponds to the substrate used. From figure 7 it can be stated that particle size also influences the devitrification process. The smaller the particle size, the lower the 
temperature at which shrinkage stops as a consequence of the new formed crystals [29] as well as the lower the temperature at which sintering reinitiates.

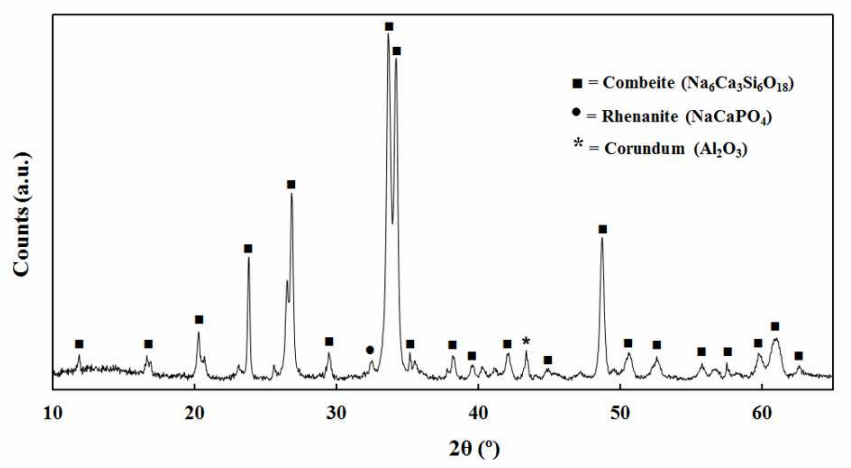

Figure 8 XRD pattern corresponding to the crystallised species at a peak temperature of $800{ }^{\circ} \mathrm{C}$

The effect of particle size can be more easily observed in DTA/TG-DTG curves. Tests performed for BGGS and BGGS3 powder fractions are shown in figure 9. Curves are very similar; exothermic peaks start at lower temperature when the particle size is smaller. For the coarse fraction (BGGS), an endothermic effect corresponding to the elimination of the structural water $\left(\mathrm{T}_{\mathrm{v}}=180^{\circ} \mathrm{C}\right)$ and another endothermic effect due to the glass transition $\left(\mathrm{T}_{\mathrm{g} 1}=520^{\circ} \mathrm{C}\right)$ occur. These two endothermic peaks are followed by an exothermic peak due to the overlapping effect of the crystallisation of two different phases (combeite and rhenanite respectively), at $\mathrm{T}_{\mathrm{c} 1}=720^{\circ} \mathrm{C}$ and $\mathrm{T}_{\mathrm{c} 2}=770{ }^{\circ} \mathrm{C}$ [26-28]. The formation of these crystalline phases is attributed to a glass phase separation that occurs after the glass transition. The process of glass phase separation is due to the high concentration of $\mathrm{Si}^{+4}$ and $\mathrm{P}^{+5}$ (high valence ions) into the starting glass [14,29]. These elements are glass network formers; hence, a rich silica phase and a rich phosphate phase are formed when temperature increases. Finally, melting occurs for a range of temperatures between $1000-1180{ }^{\circ} \mathrm{C}$. In this temperature range there are two endothermic peaks $\left(\mathrm{T}_{\mathrm{m} 1}=1060{ }^{\circ} \mathrm{C}\right.$ and $\left.\mathrm{T}_{\mathrm{m} 2}=1100{ }^{\circ} \mathrm{C}\right)$ corresponding to the partial melting of the two crystalline phases formed. Besides, another endothermic peak is observed at a temperature of $\mathrm{T}_{\mathrm{g} 2}=840{ }^{\circ} \mathrm{C}$ which is attributable to a second glass transition as reported elsewhere [26-28]. 

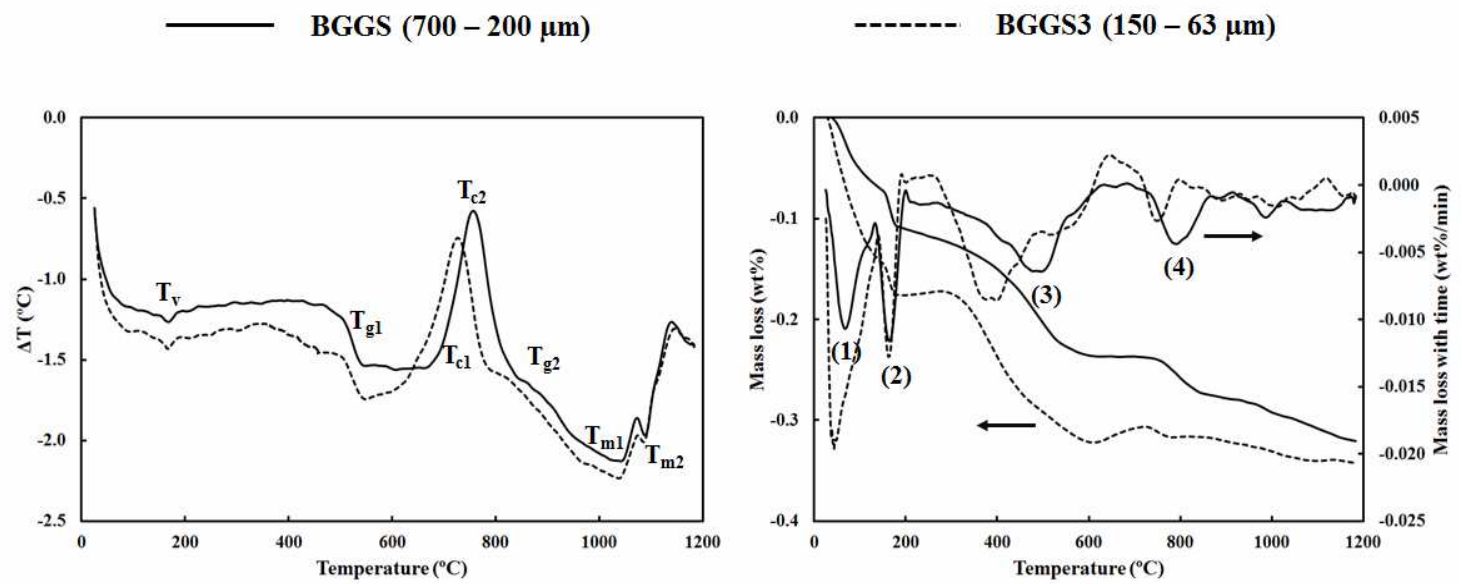

Figure 9 DTA/TG-DTG tests performed for the BGGS and BGGS3 powder fractions. Figure 9a: DTA tests. Figure 9b: TG/DTG tests.

In the case of the fine fraction (BGGS3), the effects mentioned also take place, but the crystallisation peak occurs at lower temperature.

The TG-DTG figures, in the case of the coarse fraction (BGGS), showed different weight losses. The first one (1) takes place at $80{ }^{\circ} \mathrm{C}$ and it is due to the evaporation of the free water. A second weight loss (2) occurs at $175^{\circ} \mathrm{C}$ because of the elimination of the structural water of the powder sample. In addition, a weight loss occurs (3) at $500{ }^{\circ} \mathrm{C}$ due to the elimination of the $-\mathrm{OH}$ groups and then, from $770{ }^{\circ} \mathrm{C}$ onwards (4), the sample loses weight probably due to partial evaporation of $\mathrm{Na}_{2} \mathrm{O}$ [14,26-29]. For the fine fraction (BGGS3), the above effects also take place, but at lower temperatures. On comparing the obtained DTGs, the peak of free water elimination (1) is more marked for the BGGS3 glass due to its high moisture uptake ability (higher surface area). The DTA/TG-DTG tests for the remaining powder fractions are very similar.

\subsection{Microstructure of coatings obtained from the different glass powder fractions}

All the samples of glass powder fractions were used as APS feedstocks to obtain the corresponding coatings. Table 5 describes some characteristics of the obtained coatings. 


\begin{tabular}{ccc}
\hline Powder fraction & Coating & Observation \\
\hline BGGS & No coating was obtained & Particles cannot adhere \\
BGGS1 & No coating was obtained & Similar to BGGS fraction \\
BGGS2 & Coating was obtained & Peak and valley, cracked \\
BGGS3 & Coating was obtained & Similar to BGGS2 fraction \\
& & \\
BGGS4 & No coating was obtained & No powder flowability \\
\hline
\end{tabular}

FEG-ESEM micrographs are detailed in figure 10. Coarser fractions (BGGS and BGGS1) gave no rise to coatings. The particles of these fractions could not properly melt to adhere on the substrate due to their coarse size as well as to the extremely short soaking time into the plasma plume. On the other hand, when BGGS2 and BGGS3 fractions were sprayed, coatings were obtained.
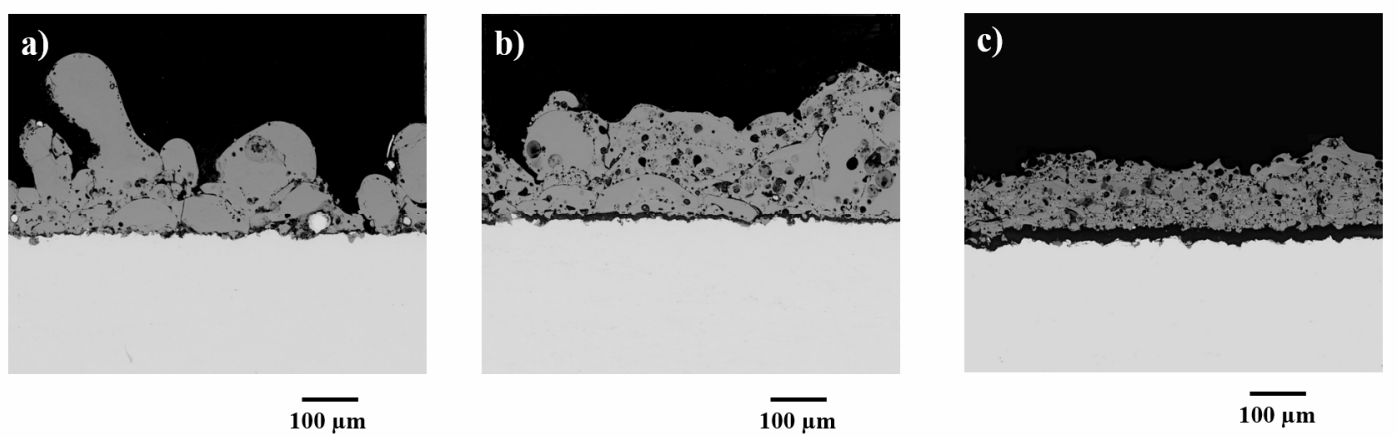

Figure 10 FEG-ESEM micrographs of the obtained coatings with (a) BGGS2, (b) BGGS3 and (c) BGGS4 (with $1 \mathrm{wt} \%$ fluidiser) powder fractions

Figure 10 shows that the coatings display the typical splat-like microstructure of plasma sprayed coatings, with peak and valley surfaces and cracks and pores inside the splat matrix [30]. Even so, the coating from the BGGS3 fraction is less irregular than that obtained from the BGGS2 fraction as a consequence of the smaller particle size of 
sample BGGS3. Unlike other APS coatings obtained from highly refractory crystalline oxides such as alumina or zirconia, the liquid phase sintering occurring during the thermal treatment of glass powders gives rise to an abundance of round pores inside the coating. These findings confirm the results obtained by Canillo et al. [10]. According to these researchers the round particles visible on the coating surface, especially in the BGGS2 coating, are the consequence of semi-melted particles in the plasma plume. Thus if the starting glass particle is too coarse the core of the particle, which is not melted, prevents the flattening of the particle, which preserves its sphere-like appearance.

For the finest particle size fraction (sample BGGS4) no coating was obtained either. This was due to its high ability of adsorbing water, which dramatically reduces the flowability of this powder preventing the feeding of the sample to the plasma by means of the pneumatic conveying system.

In order to solve the flowing problem of BGGS4, a fluidiser was added to the powder. The fluidiser used was hydrophobic fumed silica (Aerosil R812, Evonik Industries, Germany) with a mean particle size of $7 \mathrm{~nm}$ and a specific surface area of $260 \pm 30 \mathrm{~m}^{2}$ $\mathrm{g}^{-1}$. This fluidiser was chosen from previous experience on flowability enhancement with other cohesive powders. A home-made high-intensity knife-type mixer was employed to mix the fluidiser with the fine powder. Several tests were performed and the best results were obtained for a mixing time of 5 minutes and a concentration of fluidiser in the powder of $1 \mathrm{wt} \%$. FEG-ESEM micrographs of the BGGS4 fraction with fluidiser are detailed in figure 11. Micrograph (a) shows the powder fraction mixed with fluidiser and micrograph (b) shows (at high magnification) the nanometric particles of fluidiser onto the surface of the glassy powder. 


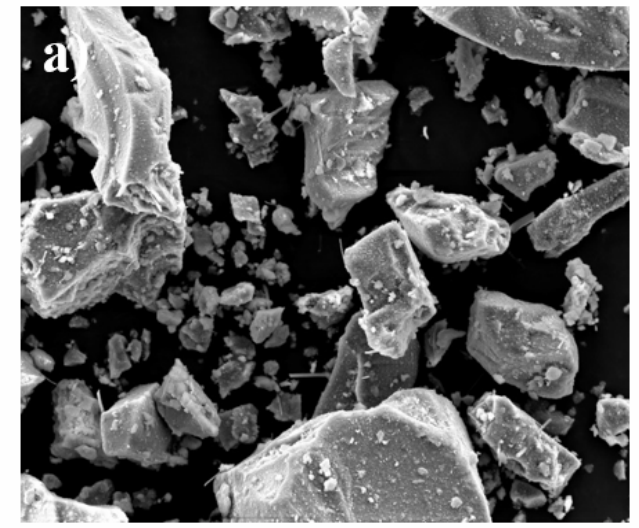

$15 \mu \mathrm{m}$

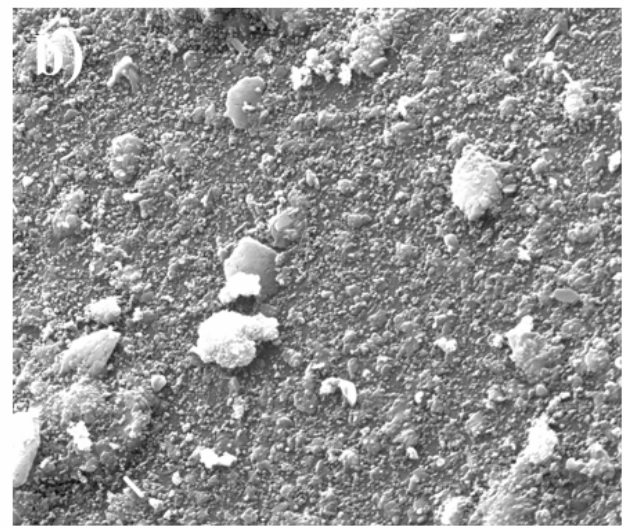

$2 \mu \mathrm{m}$

Figure 11 FEG-ESEM micrographs of the BGGS4 powder fraction with $1 \mathrm{wt} \%$ fluidiser

In order to know if the use of the fluidiser could affect the water adsorption ability of the glass powder, moisture uptake with time and the angle of repose were determined for BGGS4 powder containing fluidiser in the same way as set out with the sample of BGGS4 fraction without fluidiser. Furthermore, Hausner ratio (HR) values of the BGGS4 powder fraction with and without fluidiser are shown in figure 5 and table 6 , respectively.

Table 6 Hausner ratio variation with fluidiser content for BGGS4 powder fraction

\begin{tabular}{ccc}
\hline Powder fraction & Fluidiser content (wt\%) & Hausner ratio (HR) \\
\hline \multirow{2}{*}{ BGGS4 } & $0 \%$ & $1.40 \pm 0.03$ \\
& $1 \%$ & $1.30 \pm 0.01$ \\
\hline
\end{tabular}

HR decreased when $1 \mathrm{wt} \%$ fluidizer was added to the BGGS4 powder, that is, powder flowability improved. On the other hand, as it can be seen in figure 5 (hollow circles), the maximum values of the moisture uptake and the angle of repose $\left(\alpha_{M}\right)$ of the powder also decreased when $1 \mathrm{wt} \%$ fluidiser was added, confirming the hydrophobic character of this additive. The reduction in water adsorption with time results in a parallel decrease of the angle of repose (hollow triangles), i.e. an improvement of flowability. Consequently, the powder with fluidiser could be led into the plasma plume, allowing to obtain a coating. The FEG-ESEM micrograph of this coating is shown in figure 10c. The microstructure is similar to that of the BGGS2 and BGGS3 coatings; but, in this 
case, the surface is much more regular as a consequence of the smaller particle size of the starting powder.

As the coatings showed no or little adherence to the substrate, they were XRD analysed. The obtained XRD patterns corresponded to amorphous materials, as depicted in figure 12. Hence, the amorphous structure of the feedstocks was preserved in the obtained coatings. These findings demonstrate that the crystalline phases that appear during the thermal treatment and started to melt at temperatures between $1000{ }^{\circ} \mathrm{C}$ and $1100{ }^{\circ} \mathrm{C}$ (Figure 9), completely melt in the plasma torch as a consequence of the extremely high temperatures reached (higher than $10000{ }^{\circ} \mathrm{C}$ ). Thus, despite the effect of the particle size of the glass powder feedstock on the crystallisation phenomena the huge energy provided by the plasma ensures the melting of any of the crystalline phases newly formed when heating the glass. Besides, the rapid cooling that takes place after coating deposition impedes any devitrifying process, which can occur during the cooling of the melt for the powder feedstock.

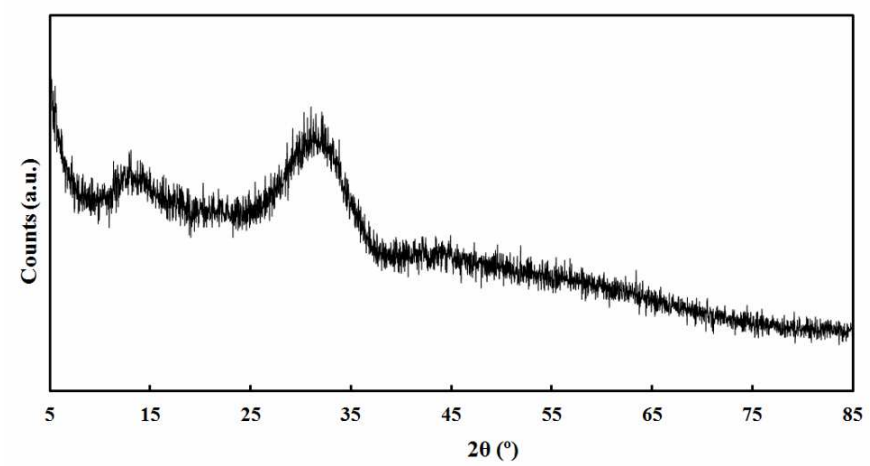

Figure 12 XRD pattern of the obtained coating starting from BGGS3 powder fraction

\section{Conclusions}

Bioactive glass powder fractions with different particle size were prepared by melting, milling and sieving. The powders, used as feedstocks for APS, showed fully amorphous character as revealed by XRD analysis.

Thermal behaviour of the feedstocks was highly dependent on their particle size. All fractions underwent the same processes (weight losses, glass transitions, crystallisations, etc). However, the smaller the particle size the lower the temperature at which most of these processes took place. 
The finest powder fraction showed highly hygroscopic behaviour, due to its higher specific surface area. Consequently, when this powder fraction adsorbs water from indoor air its flowability is seriously impaired.

With regard to the deposition of the powder fractions, at first coatings were only obtained from intermediate fractions BGGS2 $(200-100 \mu \mathrm{m})$ and BGGS3 $(150-63 \mu \mathrm{m})$. Thus, when coarse fractions (BGGS and BGGS1) were sprayed, no coating was obtained due to the low melting degree of the larger powder particles as soaking time in the plasma plume is extremely low. The finest powder fraction (BGGS4) needed a hydrophobic fluidiser in order to improve its flowability and reduce its water adsorption ability. When $1 \mathrm{wt} \%$ of fluidiser was added it was possible to obtain a coating by APS. All the obtained coatings showed amorphous character which evidenced the melting of any crystalline phase that could appear during APS deposition. The microstructure of the obtained coatings corresponded to the typical splat-like matrix of APS coatings containing pores and cracks. Nevertheless the coarser the feedstock particle size the more irregular the coating surface was as a consequence of the insufficient particle melting which prevented the flattening of some particles when impacting on the substrate. The abundance of round pores in the microstructure is consequence of a liquid phase sintering mechanism operating during the thermal treatment of glassy particles.

Concerning the adherence between coatings and substrates, no consideration was made since the aim of this work was to determine the effect of the particle size. However, this is already under study by using a bond coat as well as testing different metallic substrates.

\section{Acknowledgements}

Authors wish to acknowledge the University Jaume I of Castellon for the support in the RECUBIO project (P1-1B2013-69) and Fritta S.L. for the support in feedstock synthesis.

\section{References}

[1] Juhasz JA, Best SM (2012) Bioactive ceramics: processing, structures and properties. J Mater Sci 47:610-624

[2] De Aza PN, De Aza AH, Pena P, De Aza S (2007) Bioactive glasses and glassceramics. Bol Soc Esp Ceram V 46:45-55 
[3] Helsen JA, Proost J, Schrooten J, Timmermans G, Brauns E, Vanderstraeten J (1997) Glasses and bioglasses: synthesis and coatings. J Eur Ceram Soc 17:147152

[4] Sola A, Bellucci D, Canillo V, Cattini A (2011) Bioactive glass coatings: a review. Surf Eng 27:560-573

[5] López V, Vicent M, Bannier E, Cañas E, Sánchez E (2014) 45S5 bioactive glass coating by atmospheric plasma spraying obtained from feedstocks prepared by different routes. J Mater Sci 49:7933-7942

[6] Shirtliff VJ, Hench LL (2003) Bioactive materials for tissue engineering, regeneration and repair. J Mater Sci 38:4697-4707

[7] Monsalve M, Ageorges H, Lopez E, Vargas F, Bolivar F (2013) Bioactivity and mechanical properties of plasma-sprayed coatings of bioglass powders. Surf Coat Technol 220:60-66

[8] Bolelli G, Bellucci D, Canillo V, Lusvarghi L, Sola A, Stiegler N, Müller P, Killinger A, Gadow R, Altomare L, De Nardo L (2014) Suspension thermal spraying of hydroxyapatite: Microstructure and in vitro behaviour. Mat Sci Eng C 34:287-303

[9] Lee TM, Chang E, Wang BC, Yang CY (1996) characteristics of plasma-sprayed bioactive coatings on Ti-6Al-4V alloy: an in vitro study. Surf Coat Technol 79:170-177

[10] Canillo V, Sola A (2010) Different approaches to produce coatings with bioactive glasses: enamelling vs plasma spraying. J Eur Ceram Soc 30:2031-2039

[11] Goller G (2004) The effect of bond coat on mechanical properties of plasma sprayed bioglass-titanium coatings. Ceram Inter 30:351-355

[12] Verné E, Ferraris M, Ventrella A, Paracchini L, Krajewski A, Ravaglioli A (1998) Sintering and plasma spray deposition of bioactive glass-matrix composites for medical applications. J Eur Ceram Soc 18:363-372

[13] Davis JR (2004) Handbook of thermal spraying technology 1st edn. In: Coatings, equipment and theory. ASM International, The USA, pp 66-67

[14] Fernández Navarro JM (2003) El vidrio (The glass) 3rd edn. CSIC, Madrid

[15] Alvarez-Estrada D (1962) Formación y eliminación de burbujas en vidriados cerámicos (Formation and removal of bubbles in ceramic glazes). IV Conference of Week Ceramic Studies of the Spanish Ceramic Society, Madrid 511-526 
[16] Vicent M, Bannier E, Benavente R, Salvador MD, Molina T, Moreno R, Sánchez E (2013) Influence of the feedstock characteristics on the microstructure and properties of $\mathrm{Al}_{2} \mathrm{O}_{3}-\mathrm{TiO}_{2}$ plasma-sprayed coatings. Surf Coat Technol 220:74-79

[17] Vicent M, Bannier E, Moreno R, Salvador MD, Sánchez E (2013) Atmospheric plasma spraying coatings from alumina-titania feedstock comprising bimodal particle size distributions. J Eur Ceram Soc 33:3313-3324

[18] Popa AC, Marques VMF, Stan GE, Husanu MA, Galca AC, Ghica C, Tulyaganov DU, Lemos AF, Ferreira JMF (2014) Nanomechanical characterization of bioglass synthesized by magnetron sputtering. Thin Solid Films 553:166-172

[19] Mestre S, Bou E, Quereda P, Barba A (2001) Using the hot stage microscope for estimating frit sealing temperature. Ceram Forum Internation 78:36-39

[20] Pascual MJ, Pascual L, Durán A (2001) Determination of the viscositytemperature curve for glasses on the basis of fixed viscosity points determined by hot stage microscopy. Phys Chem Glasses 42:61-66

[21] Amoros JL, Blasco A, Enrique JE, Negre F (1987) Características de polvos cerámicos para prensado (Characteristics of ceramic powders for pressing). Bol Soc Esp Ceram Vidr 26:31-37

[22] Geldart D, Abdullah EC, Hassanpour A, Nwoke LC, Wouters I (2006) Characterizacion of powder flowability using measurement of angle of repose. China Part 4:104-107

[23] Wong AC (2002) Use of angle of repose and bulk densities for powder characterization and the prediction of minimum fluidization and minimum bubbling velocities. Chem Eng Sci 57:2635-2640

[24] Sherrington PJ, Oliver R (1980) Granulation. In: Particle-particle attractive forces 1 st edn. Heyden, London

[25] Peitl Filho O, LaTorre GP, Hench LL (1996) Effect of crystallization on apatitelayer formation of bioactive glass 45S5. J Biomed Mater Res B 30:509-514

[26] Lefebvre L, Chevalier J, Gremillard L, Zenati R, Thollet G, Bernache-Assolant D, Govin A (2007) Structural transformations of bioactive glass 45S5 with thermal treatments. Acta Mater 55:3305-3313

[27] Lefebvre L, Gremillard L, Chevalier J, Zenati R, Bernache-Assolant D (2008) Sintering behaviour of 45S5 bioactive glass. Acta Biomater 4:1894-1903 
[28] Bretcanu O, Chatzistavrou X, Paraskevopoulos K, Conradt R, Thompson I, Boccaccini AR (2009) Sintering and crystallisation of 45S5 Bioglass ${ }^{\circledR}$ powder. J Eur Ceram Soc 29:3299-3306

[29] Boccaccini AR, Chen Q, Lefebvre L, Gremillard L, Chevalier J (2007) Sintering, crystallisation and biodegradation behaviour of Bioglass ${ }^{\circledR}$-derived glass-ceramic. Faraday Discuss 136:27-44

[30] Pawlowski L (2008) The Science and Engineering of Thermal Spray Coatings 2nd edn. John Wiley \& Sons, Great Britain 